\title{
Age and sharing of needle injection equipment in a cohort of Massachusetts injection drug users: an observational study
}

\author{
Katherine Tassiopoulos ${ }^{1 *}$, Judith Bernstein ${ }^{2}$ and Edward Bernstein ${ }^{3}$
}

\begin{abstract}
Background: Hepatitis C infection (HCV) among individuals aged 15-24 years has increased in Massachusetts, likely due to injection drug use. The prevalence of injection equipment sharing (sharing) and its association with age was examined in a cohort of out-of-treatment Massachusetts substance users.

Methods: This analysis included baseline data from a behavioral intervention with substance users. Younger and older ( $<25$ versus $\geq 25$ years) injection drug users were compared on demographic characteristics, substance use practices, including factors present during the most recent sharing event ("event-level factors"), and HCV testing history.

Results: Sharing was reported by $41 \%$ of the 484 individuals who reported injection drug use in the past 30 days. Prevalence of sharing varied by age $(50 \%<25$ years old versus $38 \% \geq 25$ years, $p=0.02)$. In a multivariable logistic regression model younger versus older individuals had twice the odds of sharing $(95 \% \mathrm{Cl}=1.26,3.19)$. During their most recent sharing event, fewer younger individuals than older had their own drugs available (50\% versus $75 \%$, $p<0.001$ ); other injection event-level factors did not vary by age. In the presence of PTSD, history of exchanging sex for money, or not being US born, prevalence of sharing by older users was higher and was similar to that of younger users, such that there was no association between age and sharing.

Conclusions: In this cohort of injection drug users, younger age was associated with higher prevalence of sharing, but only in the absence of certain stressors. Harm reduction efforts might benefit from intervening on mental health and other stressors in addition to substance use. Study findings suggest a particular need to address the dangers of sharing with young individuals initiating injection drug use.
\end{abstract}

Keywords: Injection drug use, Injection equipment sharing, Young age, Hepatitis C

\section{Background}

A recent Morbidity and Mortality Weekly Report (MMWR) found that, between 2002 and 2009, the rate of hepatitis $\mathrm{C}$ (HCV) infection increased statewide among young people (15-24 years of age) in Massachusetts, primarily among non-Hispanic whites. The investigators identified injection drug use as the primary risk factor for $\mathrm{HCV}$ infection in this population of adolescents and young adults, with heroin being the primary drug of injection [1]. During this same time period there was

\footnotetext{
* Correspondence: ktassiop@hsph.harvard.edu

'Department of Epidemiology, Harvard School of Public Health, 677

Huntington Ave., Boston, MA, USA

Full list of author information is available at the end of the article
}

also an apparent increase in heroin use among young people in Massachusetts and other states [2].

In light of these recent findings, it is important to understand the connection between age and injection drug use and sharing of injection drug use equipment in particular. Shared use of injection drug equipment (sharing) is a strong risk factor for HCV infection [3]. While a few studies of injection drug users have found either no association with age and sharing $[4,5]$ or have found that older age is a risk factor [6], most studies have reported that younger injection drug users are more likely than older users to share needles or other drug equipment [7-13]. The reasons for the observed association between younger age and sharing are multifactorial. New initiates into injection
Ciomed Central 
drug use do not have experience injecting and may thus require help from others [14]; they also may have not been adequately exposed to prevention messages about the risks of sharing [15]. Additionally, young users may learn to inject in the context of strong social networks that encourage sharing and where trust and friendship make sharing more comfortable and less risky [16]. What has not been previously explored is whether this association between younger age and sharing holds steady across all cohorts of injection drug users or whether there are factors that might modify this association, as is suggested by the seemingly contradictory findings mentioned above.

The overall objective of this study was to further the understanding of why younger individuals are often more likely to share injection drug equipment, and to identify factors that might modify this association. Toward this end we examined data from a cohort of Greater Boston area injection drug users followed during the period in which HCV infection in Massachusetts was observed to increase. Our primary aims were to: (1) describe demographic and drug use practices overall and by age $(<25 / \geq 25$ years, to correspond to the upper age for which $\mathrm{HCV}$ infection was observed to increase in Massachusetts); (2) estimate the association between age and sharing, adjusting for other risk factors of sharing; (3) compare younger ( $<25$ years) and older ( $\geq 25$ years) individuals on factors present at their most recent sharing injection event; (4) explore whether the association between age and sharing varies between levels of factors indicative of personal stressors or social instability, including exchange of sex for money, post-traumatic stress disorder (PTSD) symptoms, and whether US born; and (5) summarize the self-reported HCV testing history and the HIV prevalence of injection drug users in the cohort, overall, by age group, and by sharing status.

\section{Methods \\ Study sample}

The parent study from which this analysis is drawn was a randomized controlled trial of a behavioral intervention to reduce sexual risk behaviors among hospital patients who reported drug use within the past 30 days. An ethnically diverse population of patients registered for medical care from November 2004 through May 2008 was screened for eligibility at an academic, urban, level-I, trauma center emergency department using a Health Needs History screening survey [17]. Eligibility criteria for the parent study included current (past 30-day) cocaine or heroin use, English or Spanish speaking, ages 18-54 years, and a Drug Abuse Severity Test Score $\geq 3$ indicating moderate or higher severity [18]. In the current analysis, we included all enrollees from the parent study who reported injection drug use at the baseline visit. The study was approved by the Boston University Medical Campus Institutional
Review Board, and written informed consent was obtained for all enrollees. A National Institutes of Health Certificate of Confidentiality was obtained to protect subject data from subpoena. Details of the enrollment process and intervention are described elsewhere [19].

\section{Study design and laboratory procedures}

The present study is a cross-sectional analysis that used data collected at the baseline visit of the intervention study. Enrolled participants were interviewed face-to-face by trained research assistants for demographic characteristics, health status, drug use patterns, sexual practices, HCV testing history, and PTSD symptoms using the PTSD Checklist-Civilian Version (PCL-C) [20]. Testing for HIV infection was conducted using oral mucosal transudate (OMT) samples (OraQuick ${ }^{\bullet}$, Orasure Technologies, Inc.) processed by the Massachusetts Department of Public Health Laboratory. The OMT specimens were tested for HIV antibodies by enzyme-linked immunosorbent assay (ELISA) and confirmed by western blot. Testing for HCV was not conducted.

\section{Exposure}

The primary exposure of interest was age, dichotomized as younger ( $<25$ years) or older ( $\geq 25$ years). This definition of younger and older age was chosen $a$ priori to correspond to the upper age for which hepatitis rates increased in Massachusetts (15-24 years of age) as described in the $M M W R$ [1]. We also considered age as a categorical $(18-25,>25-40$, and $>40$ years $)$ and a continuous variable in Aim 2 to further explore the association of age with sharing.

\section{Outcome}

The outcome for Aims 2 and 4 was any disclosure of shared needles or other injection drug use equipment within the past 30 days based on responses to the question: "In the past 30 days when you injected drugs, how often did you use shared needles or works?" Responses varied from 'never', 'sometimes', 'often', and 'always'. For these analyses, 'any use' was defined as a report of 'sometimes', 'often', or 'always' sharing.

\section{Covariates}

We considered as potential confounders of the association between age and sharing (Aim 2) several risk factors for sharing identified in the literature, including: race; gender; education level (less than high school or high school and higher); current working status; living status (homeless, staying in shelter, or living temporarily with friends or family versus living in house, apartment, public housing, rooming house, halfway house, or group home); frequency of injection use in the past 30 days; specific drugs used in the past 30 days (injected or otherwise) (heroin, 
cocaine/crack, marijuana, PCP, speed/amphetamines, inhalants, barbiturates, benzodiazepines, hallucinogens); PTSD symptoms; history of receiving money in exchange for sex; and whether US born (defined as born in the US excluding Puerto Rico and other territories).

\section{Event-level factors}

For Aim 3, we compared the prevalence of factors present during the most recent sharing episode ("event-level factors") for younger and older injectors. In particular, we explored the type of drug shared, whether the individual had their own drugs to inject, the type of injection partner, whether the individual experienced withdrawal symptoms before injection, the setting of the sharing event, and where the individual obtained the needles used in the sharing event. These factors are important in defining the context of a recent sharing event; differences in the prevalence of these factors by age can help elucidate when and why younger and older individuals share.

\section{Effect modifiers}

We also had an a priori interest in examining a subset of the covariates summarized above as potential effect modifiers of the association between age and sharing (Aim 4) because of their association with life stressors or social instability: history of receiving money in exchange for sex; PTSD symptoms; and whether US born.

\section{HCV and HIV testing}

Participants were also asked whether they had ever been tested for HCV. If they answered 'yes', they were asked whether they had received their test results, and if so, whether the results were positive or negative. This information, and the results of HIV testing, were summarized for the group as a whole, both by age group and by sharing status (Aim 5).

\section{Statistical analysis}

We summarized study sample characteristics, including demographics, drug using practices, HCV testing history, and HIV serostatus. We compared younger and older injection drug users by these characteristics using chisquare tests. Among those individuals who reported any sharing, we compared factors present during the most recent sharing event (event-level factors) for younger versus older users using chi-square tests, to explore differences in prevalence for younger versus older users who shared.

We used logistic regression models to estimate the association between age and sharing. A univariable model with dichotomous age as the sole predictor was first developed to provide an unadjusted odds ratio (OR) for the association of age with sharing. A multivariable model was then built to estimate the association of age and sharing, adjusting for confounding factors. Each potential confounder of the association between age and sharing was entered into the univariable model one at a time. When inclusion of a specific variable changed the OR for the unadjusted association between age and sharing by more than $10 \%$, this variable was included in the final multivariable model as a confounder. Univariable and multivariable models with (a) continuous and (b) categorical age were also developed; the multivariable models included the covariates identified as confounders in the primary (dichotomous age) multivariable model.

To explore effect modification, we stratified multivariable models (which included covariates identified as confounders for Aim 2) of age and sharing by the categories of each potential effect modifier (history of receiving money in exchange for sex, PTSD symptoms, whether US born) to determine whether the association between age and sharing differed between these different categories. (For instance, we examined whether the association between age and sharing was different for those with PTSD symptoms and for those without symptoms). In those situations where there was qualitative evidence of effect modification (for example, no association observed in one category of the effect modifier but a strong association observed in another category), we created interaction terms between age and the covariate and included this term in the model to determine whether the interaction term was statistically significant.

\section{Results}

One thousand thirty substance users were enrolled in the intervention study. Four hundred eighty-nine individuals (47.5\%) reported having injected drugs within the past 30 days. Our analysis sample included the 484 injectiondrug-using individuals (99\%) who provided information on whether they had shared injection equipment within the past 30 days. One hundred one of the 484 individuals (20.9\%) were <25 years of age (18.9-24.9 years), and 383 (79.1\%) were $\geq 25$ years of age (25.2-54.3 years).

Table 1 summarizes the demographic and behavioral characteristics of the study sample, stratified by age. Several factors differed by age. Fifty-one percent of younger users were female compared with $33 \%$ of older users $(\mathrm{p}<0.01)$. Eighty-seven percent of younger users were white non-Hispanic compared with $53 \%$ of older users $(\mathrm{p}<0.01)$. Frequency of cocaine use also differed by age, with twice as many older users reporting daily cocaine use $(21.0 \%$ versus $10.1 \%, \mathrm{p}=0.01)$. The majority reported both daily use of heroin and daily injection drug use; these proportions did not differ by age.

One hundred ninety-eight of 484 (40.9\%) injection drug users reported having shared within the past 30 days. This proportion differed by age: approximately 50\% of 
Table 1 Characteristics of out-of-treatment injection drug users, by age $(\mathrm{N}=\mathbf{4 8 4})$

\begin{tabular}{|c|c|c|c|}
\hline Characteristic & $\begin{array}{c}\text { Younger than } 25 \\
(\mathrm{~N}=101) \mathrm{N}(\%)\end{array}$ & $\begin{array}{c}25 \text { or older } \\
(\mathrm{N}=383) \mathrm{N}(\%)\end{array}$ & p-value \\
\hline Female & $52(51.5)$ & $125(32.6)$ & $<0.01$ \\
\hline Race & & & $<0.01$ \\
\hline Black & $1(1.0)$ & $54(14.1)$ & \\
\hline White, non-Hispanic & $88(87.1)$ & $204(53.3)$ & \\
\hline Hispanic & $11(10.9)$ & $120(31.3)$ & \\
\hline Other & $1(1.0)$ & $5(1.3)$ & \\
\hline Born in US & $95(94.1)$ & $332(86.7)$ & 0.04 \\
\hline Homeless & $45(44.6)$ & $195(50.9)$ & 0.26 \\
\hline Education $\geq$ High School & $74(73.3)$ & $257(67.1)$ & 0.24 \\
\hline Currently Working & $17(16.8)$ & $34(8.9)$ & 0.02 \\
\hline $\begin{array}{l}\text { PTSD Symptoms } \\
\text { Score }>50\end{array}$ & $59(58.4)$ & $211(55.2)$ & 0.57 \\
\hline $\begin{array}{l}\text { Frequency of } \\
\text { Cocaine/Crack Use }\end{array}$ & & & 0.01 \\
\hline No use & $33(33.3)$ & $152(39.9)$ & \\
\hline 1-3 times per month & $22(22.2)$ & $57(15.0)$ & \\
\hline 1-6 times per week & $34(34.4)$ & $92(24.1)$ & \\
\hline Daily & $10(10.1)$ & $80(21.0)$ & \\
\hline $\begin{array}{l}\text { Frequency of } \\
\text { Heroin Use }\end{array}$ & & & 0.60 \\
\hline No use & $5(5.2)$ & $10(2.6)$ & \\
\hline $1-3$ times per month & $12(12.5)$ & 44 (11.6) & \\
\hline 1-6 times per week & $11(11.5)$ & $50(13.2)$ & \\
\hline Daily & $68(70.8)$ & $276(72.6)$ & \\
\hline $\begin{array}{l}\text { Frequency of Injection } \\
\text { Drug Use }\end{array}$ & & & 0.86 \\
\hline 1-3 times per month & $15(15.5)$ & $56(14.7)$ & \\
\hline 1-6 times per week & $14(14.4)$ & $48(12.6)$ & \\
\hline Daily & $68(70.1)$ & $277(72.7)$ & \\
\hline $\begin{array}{l}\text { History of Exchanging } \\
\text { Sex for Money }\end{array}$ & $26(25.7)$ & $93(26.5)$ & 0.92 \\
\hline $\begin{array}{l}\text { Any Needle Sharing, } \\
\text { past } 30 \text { days }\end{array}$ & $52(51.5)$ & $146(38.1)$ & 0.02 \\
\hline
\end{tabular}

The following variables had missing observations: PTSD symptoms $(n=1)$; cocaine/ crack frequency $(n=4)$; heroin frequency $(n=8)$; injection frequency $(n=6)$.

individuals $<25$ years reported sharing compared with $38 \%$ of those $\geq 25$ years $(\mathrm{p}=0.02)$.

The unadjusted OR for the association between younger age and sharing was 1.72 (95\% confidence interval $[95 \% \mathrm{CI}]=1.11,2.68)$. In the final multivariable model, younger injection drug users had twice the odds of sharing of older users $(95 \% \mathrm{CI}=1.26,3.19)$ (Table 2). Variables that were included in the final model as confounders of the association between age and sharing included frequency of cocaine/crack use, injection frequency, and whether US born. Those who reported using cocaine or
Table 2 Association between age and sharing of injection drug equipment $(\mathrm{N}=484)$

\begin{tabular}{|c|c|c|c|}
\hline Characteristic & $\begin{array}{l}\text { Unadjusted } \\
\text { model }\end{array}$ & $\begin{array}{c}\text { Multivariable } \\
\text { model }\end{array}$ & P-value \\
\hline Age in years & & & 0.004 \\
\hline$<25$ & $1.72(1.11,2.68)$ & $1.99(1.25,3.18)$ & \\
\hline$\geq 25$ & ref & ref & \\
\hline $\begin{array}{l}\text { Frequency of } \\
\text { Cocaine/Crack Use }\end{array}$ & & & 0.002 \\
\hline Daily & & $2.75(1.62,4.68)$ & \\
\hline 1-6 times per week & & $1.87(0.90,3.03)$ & \\
\hline 1-3 times per month & & $1.61(0.90,2.85)$ & \\
\hline No use & & ref & \\
\hline Born outside US & & $2.09(1.16,3.79)$ & 0.02 \\
\hline $\begin{array}{l}\text { Frequency of Injection } \\
\text { Drug Use }\end{array}$ & & & 0.24 \\
\hline Daily & & $1.59(0.90,2.82)$ & \\
\hline 1-6 times per week & & $1.73(0.82,3.62)$ & \\
\hline 1-3 times per month & & ref & \\
\hline
\end{tabular}

crack daily had 2.75 times the odds of sharing of those who did not use cocaine or crack. Those who were born outside the US had twice the odds of sharing of those born in the US. Injection frequency was not associated with sharing in the multivariable model. Gender, education level, and homelessness did not confound the association between age and sharing. The adjusted OR for continuous age and sharing was $0.96(95 \% \mathrm{CI}=0.94,0.98)$. The adjusted OR for individuals $>25-40$ years (versus $18-25$ years) was $0.61(95 \% \mathrm{CI}=0.38,0.99)$, and for individuals older than 40 years (versus $18-25$ years) was 0.29 (95\% $\mathrm{CI}=0.16,0.53$ ).

Table 3 summarizes the event-level factors present during the most recent sharing event for the 198 individuals who reported sharing, stratified by age group. A significantly lower proportion of younger than older individuals said that they had their own drugs available for injection $(50 \%$ versus $75 \%, \mathrm{p}<0.001)$. Most individuals (77\%), regardless of age, reported using heroin during their most recent sharing event, and the majority also reported experiencing withdrawal symptoms prior to injecting. A somewhat lower proportion of younger than older users reported injecting either at their home or that of a friend, but this difference was not statistically significant. A higher proportion of younger than older users reported being with a sexual partner $(42 \%$ versus $27 \%$ ), but overall the difference was not statistically significant. Most individuals obtained their needles at either a needle exchange or pharmacy. 
Table 3 Event-level characteristics at most recent drug injection equipment sharing event $(\mathrm{N}=198)$

\begin{tabular}{|c|c|c|c|}
\hline $\begin{array}{l}\text { Event-level } \\
\text { characteristic }\end{array}$ & $\begin{array}{l}\text { Younger than } 25 \\
(n=52) n(\%)\end{array}$ & $\begin{array}{c}25 \text { or older } \\
(n=146) n(\%)\end{array}$ & P-value \\
\hline Had Own Drugs & $26(50.0)$ & $109(74.7)$ & 0.001 \\
\hline Type of Drug Injected & & & 0.50 \\
\hline Heroin & $42(80.8)$ & $110(75.3)$ & \\
\hline Cocaine & $4(7.7)$ & $7(4.8)$ & \\
\hline Heroin and Cocaine & $6(11.5)$ & $28(19.2)$ & \\
\hline Other & $0(0)$ & $1(0.7)$ & \\
\hline Injection Setting & & & 0.20 \\
\hline Shooting Gallery & $2(3.9)$ & $7(4.8)$ & \\
\hline Home/Friend's Home & $21(41.2)$ & $80(54.8)$ & \\
\hline Public Place & $28(54.9)$ & $59(40.4)$ & \\
\hline Injection Partner & & & 0.22 \\
\hline Sexual Partner & $22(42.3)$ & $40(27.4)$ & \\
\hline Friends & $19(36.5)$ & $74(50.7)$ & \\
\hline Stranger(s) & $2(3.9)$ & $7(4.8)$ & \\
\hline Alone & $9(17.3)$ & $25(17.1)$ & \\
\hline $\begin{array}{l}\text { Where Obtained } \\
\text { Needles }\end{array}$ & & & 0.36 \\
\hline Needle Exchange & $25(49.0)$ & $87(60.0)$ & \\
\hline Injection Partner(s) & $7(13.7)$ & $22(16.2)$ & \\
\hline Pharmacy & $18(35.3)$ & $35(34.1)$ & \\
\hline Found & $1(2.0)$ & $1(0.7)$ & \\
\hline $\begin{array}{l}\text { Withdrawal Symptoms } \\
\text { before Injection }\end{array}$ & $40(76.9)$ & $111(76.0)$ & 0.90 \\
\hline
\end{tabular}

Missing observations: Setting=1; Where Obtained Needles=2.

The association between age and sharing differed between categories of each potential effect modifier, including PTSD positivity, receipt of money for sex, and whether US born (Table 4). Specifically, among individuals with a PTSD symptom score $\leq 50$ (indicating fewer PTSD symptoms), younger individuals had four times the odds of sharing of older individuals, while among those with a PTSD symptom score $>50$, there was no association between age and sharing. Similarly, among those with no history of receiving money for sex, younger individuals had more than twice the odds of sharing of older individuals, but no association was observed among those with a history of receiving money for sex. For those born in the US, there was a strong association between younger age and sharing, but among those born outside the US, there was no association between age and sharing.

Among those without PTSD, 60\% of younger and 30\% of older users shared $(\mathrm{p}<0.01)$, while among those with PTSD, $45 \%$ of both age groups reported sharing $(\mathrm{p}=0.87)$. Among those not reporting exchange of money for sex, a significantly higher proportion of the younger injection drug users reported sharing (55\% versus 35\% $[\mathrm{p}<0.01]$ ); but among those who said they had received money in exchange for sex, about $50 \%$ of both younger and older individuals reported sharing $(\mathrm{p}=0.58)$. We observed a similar pattern for place of birth: among those born in the US, younger individuals were more likely than older to report sharing ( $54 \%$ versus $35 \%, \mathrm{p}<0.01$ ), while among those not born in the US, there was greater reporting of sharing among older users $(61 \%$ versus $17 \%, \mathrm{p}=0.04)$, although the numbers in these cells were very small.

Overall, $77 \%$ of the study sample reported having been tested for $\mathrm{HCV}$, and there was no difference in testing by age $(p=0.22)$. Most individuals $(95 \%)$ received their test results, again with no difference by age $(\mathrm{p}=0.30)$. Among those who received their HCV test results, younger individuals were somewhat less likely to report having tested positive (62\% versus $71 \%$ ), but this difference was not statistically significant $(\mathrm{p}=0.33)$. There was also no difference in HCV testing patterns between those who reported current sharing and those who did not $(\mathrm{p}=0.66)$;

Table 4 Effect modification of the association between age and sharing of injection drug equipment

\begin{tabular}{|c|c|c|c|c|c|c|}
\hline Age, yrs (n) & $\%$ Share & OR $(95 \% \mathrm{CI})$ & Age, yrs (n) & $\%$ Share & OR $(95 \% \mathrm{Cl})$ & $\begin{array}{c}\mathrm{p} \text {-value for } \\
\text { interaction term }\end{array}$ \\
\hline \multicolumn{3}{|c|}{ PTSD Symptoms Score $\leq 50(n=213)$} & \multicolumn{3}{|c|}{ PTSD Symptoms Score $>50(n=270)$} & \multirow{3}{*}{0.09} \\
\hline$<25: n=42$ & $59.5 \%$ & $4.07(1.89,8.77)$ & $<25: n=59$ & $45.5 \%$ & $1.29(0.69,2.39)$ & \\
\hline$\geq 25: n=171$ & $30.4 \%$ & ref & $\geq 25: \mathrm{n}=211$ & $44.6 \%$ & ref & \\
\hline \multicolumn{3}{|c|}{ No History of Money for Sex $(n=332)$} & \multicolumn{3}{|c|}{ History of Money for Sex $(n=119)$} & \multirow{3}{*}{0.05} \\
\hline$<25: n=74$ & $55.4 \%$ & $2.67(1.52,4.66)$ & $<25: n=26$ & $42.3 \%$ & $0.89(0.34,2.34)$ & \\
\hline \multirow[t]{2}{*}{$\geq 25: n=258$} & $34.5 \%$ & ref & $\geq 25: n=93$ & $48.4 \%$ & ref & \\
\hline & in US $(n=$ & & & utside US & & \multirow{3}{*}{$<0.01$} \\
\hline$<25: n=95$ & $53.7 \%$ & $2.37(1.46,3.86)$ & $<25: \mathrm{n}=51$ & $16.7 \%$ & $0.15(0.01,1.99)$ & \\
\hline$\geq 25: n=332$ & $34.6 \%$ & ref & $\geq 25: \mathrm{n}=6$ & $60.8 \%$ & ref & \\
\hline
\end{tabular}

$\mathrm{N}=33$ missing information on receipt of money for sex.

Models are adjusted for frequency of cocaine injection, frequency of injection drug use, and (except for model of effect modification by US born) whether US born. Sharing is defined as any sharing of injection drug equipment in the past 30 days. 
however, among those who received their test results, those who reported sharing injection equipment were significantly more likely to report testing positive $(80 \%$ versus $62 \%, \mathrm{p}<0.01)$.

Ten percent of those 25 years and older, and $5 \%$ of those younger than 25 years, tested positive for HIV $(\mathrm{p}=0.17)$. The prevalence of HIV infection did not differ between those reporting shared use of injection equipment and those reporting no sharing $(7.6 \%$ versus $10.5 \%, \mathrm{p}=0.43)$.

\section{Discussion}

In this paper, we describe a cohort of injection drug users whose primary drug of choice was heroin. The demographic makeup of the cohort varied by age, with individuals $<25$ years old more likely to be female and white non-Hispanic. The cohort was comprised of individuals with fairly severe substance use, with the majority reporting daily injection use and daily heroin use. In addition, most reported experiencing withdrawal symptoms prior to their most recent injection equipment sharing event.

Injection drug use frequency did not vary by age; however, sharing of injection equipment did vary by age, with individuals $<25$ years old significantly more likely to share than individuals $\geq 25$ years old. Our findings are consistent with those of most previous studies that examined the association between age and sharing. This association remained strong after adjusting for several risk factors of sharing including frequency of cocaine use, frequency of injection, and whether US born. We did not have information on age at initiation of injection drug use. However, it is reasonable to propose that younger individuals in our cohort on average initiated injection drug use more recently than did older individuals. Since people are often introduced to injection drug use by other users, one reason for the association between younger age and sharing may be that younger, newer users still rely on others' help when injecting [14]. Our finding that younger individuals who share were more likely than older individuals to report that they did not have their own drugs to inject is consistent with this reason. Use and abuse of prescription opioids is also high among young individuals and has emerged as an important introduction to heroin use and heroin injection [21]. It is believed to be one of the reasons for the recent increase in injection drug use and HCV infection in young adults observed in Massachusetts and elsewhere [22].

While younger age was, overall, a strong risk factor for sharing, we found this association differed qualitatively depending on other factors that may be related to personal stressors or social instability. To our knowledge, this is the first study to have examined and identified potential effect modifiers of the association between age and sharing. Specifically, we found that the effect of younger age on sharing was substantial and significant among individuals who were born in the US, who did not have a history of receiving money for sex, or who did not have symptoms of PTSD. However, among those with one or more of these stressors, younger age was not associated with sharing. While we emphasize that these effect modification analyses and results are exploratory, they do suggest that, in the presence of other destabilizing factors in the lives of injection drug users, sharing is more prevalent among all ages, and the relative importance of younger age as a risk factor for sharing is diminished.

We found evidence that, in the presence of these stressors, the prevalence and frequency of sharing by older users was greater and more similar to that of younger users, than in the absence of these stressors. Previous research has found that older users or individuals with more extensive injection drug use experience are less likely to share than are younger users, either because they have learned how to inject on their own or because they have learned the health risks of sharing injection equipment [23]. However, it could be that in the chronic presence of stressors such as PTSD or exchange sex, individuals are not able to develop the capacity to reduce their frequency of sharing as they get older. It may also be that individuals with these stressors have less stable or more frequently changing social networks, something which has also been associated with more risky drug using behavior [24,25]. Factors specific to the social networks or life stressors of injection drug users may in part explain the conflicting results of previous studies regarding age and injection equipment sharing. For example in Stein et al. [5], where age was not significantly associated with sharing, all study participants met $D S M-I V$ criteria for major depressive disorder, dysthymia, or persistent substance-induced mood disorder.

Our results revealed greater reporting of sharing by those born outside of the US. Most of the individuals in our cohort who were born outside of mainland US were born in Puerto Rico. Zerden et al. [26] recently showed that Puerto Ricans born and residing in Puerto Rico were more likely to share needles than were Puerto Ricans born in the US and residing in Massachusetts.

Previous research has found that young injection drug users have lower rates of $\mathrm{HCV}$ testing than older users [27]. We did not observe the same finding in our cohort. This may be due to the fact that these individuals were identified in a clinical setting with minimal financial barriers to care, and may, therefore, have had more access to health care and testing services than other populations of injecting drug users.

It is worth commenting that syringe and needle exchange and legal access to over-the-counter purchases have been successful public health strategies in Massachusetts; however, in our study, the majority of individuals who 
reported sharing said the equipment used in their most recent sharing event was obtained at either needle exchange or pharmacy, and most individuals who were tested for $\mathrm{HCV}$ reported testing positive. Access to clean equipment for these individuals has, therefore, not translated into sufficient protection against HCV infection. Strategies to address the precursors of sharing are critically needed.

Our study has several limitations related to the crosssectional nature of the analyses. The lower prevalence of sharing observed for older users might not be due to safer injecting practices, but may instead be due to an overall reduction in substance use or in injection frequency over time, thereby reducing the opportunity for sharing. However, in our cohort, the frequency of injection drug use as well as the frequency of heroin use (the drug most individuals reported injecting) did not differ for older and younger users. Alternatively, the lower prevalence of sharing could be due to a survivor effect, where older individuals with years of sharing injection drug equipment do not survive and are not represented in our cohort. We are not able to assess this likelihood in the present study.

We did not have information on age at initiation of injection drug use and, therefore, cannot confirm that younger users initiated injection drug use more recently than older users. We did not collect information on the social networks of our participants; the potential influence of social networks on the association between age and sharing should be specifically assessed in future investigations. Our examination of effect modification was exploratory, as the study was not designed to examine effect modification and was, therefore, not optimally powered to identify statistically significant modifiers. Future studies with larger study samples should examine the same and additional effect modifiers related to social stress and instability, such as stressful life events and social support.

Also, since our cohort was comprised of injection drug users registered for health care at a busy urban emergency department, they are not necessarily representative of all injection drug users in Massachusetts. We did not conduct $\mathrm{HCV}$ testing and instead relied on self-reported information on $\mathrm{HCV}$ testing practices, which may mean that the observed prevalence of $\mathrm{HCV}$ testing was subject to recall bias. However, we did conduct HIV testing, and HIV test results were highly consistent with individuals' self-reports of their HIV serostatus, suggesting that biased reporting of $\mathrm{HCV}$ testing patterns was minimal (data not shown).

\section{Conclusions}

Most of the individuals in our cohort, regardless of age, reported daily heroin use and daily drug injection. Many of the individuals, again regardless of age, reported symptoms of PTSD, were homeless, or were not currently working, and older individuals reporting these stressors were more likely to share. Therefore, our findings suggest that harm-reduction efforts for these individuals should incorporate not just efforts to reduce drug injection and sharing of drug equipment, but also should address larger disruptive aspects of these individuals' lives-such as mental health and social instability. In addition, as other investigations have pointed out, prevention and harm-reduction efforts for younger individuals who have just begun to inject should continue to ensure that these individuals are knowledgeable regarding the risks of sharing $[28,29]$.

\section{Competing interests}

The authors declare that they have no competing interests.

\section{Authors' contributions}

KT: Corresponding author, who performed the statistical analysis, interpreted the data and led the writing and editing. EB: Principal investigator, who designed and conducted the study, trained coders, reviewed and offered substantive critiques and revisions to manuscript drafts throughout the process. JB: Co-principal investigator, who designed and conducted the study, trained coders, reviewed and offered substantive critiques and revisions to manuscript drafts throughout the process. All authors read and approved the final manuscript.

\section{Acknowledgments}

Funding for this study was provided by National Institute of Drug Abuse (NIDA), RO1 DA017061. NIDA had no further role in study design; in the collection, analysis and interpretation of data; in the writing of the report; or in the decision to submit the paper for publication. We thank the patients for their participation in this study. We acknowledge the dedicated contributions of study coordinators Ann Valentine, Desire Ashong, and Whitney Holmer; follow-up coordinator Belinda Gilmere; and research assistants Michael Aguiar, Manuel Andrade, William Atherton, Jephthe Barthe, Ruben Codero, Jasmine Cromwell, Michelson Dorime, Helen Fassil, Darius Franklin, Richard Frazier, Suzanne Garverich, Robin Goffigan, Gregory Hastings, Judy Headley, Robert Johnson, Nicolasa Lopez, Yvonne Martinez, Jamilah Kim Mason, Virginia Mojica, Allison Molenda, Esosa Ogboghodo, Melissa Rambaud, Miguel Risco, Raymond Rodriguez, Devorath Ruiz, Stephanie Stapleton, Pamela Talbert, Kathy Vazquez, and Ebonie Woolcock.

\section{Author details}

1Department of Epidemiology, Harvard School of Public Health, 677 Huntington Ave., Boston, MA, USA. ${ }^{2}$ Department of Community Health Sciences, Boston University School of Public Health, 801 Massachusetts Ave., Boston, MA, USA. ${ }^{3}$ Department of Emergency Medicine, Boston University School of Medicine, Boston Medical Center, 1 Boston Medical Center Place, Boston, MA, USA.

Received: 8 February 2013 Accepted: 2 December 2013 Published: 13 December 2013

\section{References}

1. Centers for Disease Control and Prevention (CDC): Hepatitis C virus infection among adolescents and young adults-Massachusetts, 2002-2009. MMWR Morb Mortal Wkly Rep 2011, 60:537-541.

2. National Drug Intelligence Center, US Department of Justice: National Drug Threat Assessment 2010. 2010 [http://www.justice.gov/archive/ndic/pubs38/ 38661/]

3. Hagan H, Thiede H, Weiss NS, Hopkins SG, Duchin JS, Alexander ER: Sharing of drug preparation equipment as a risk factor for hepatitis C. Am J Public Health 2001, 91:42-46.

4. Latkin C, Buchanan A, Metsch L, Knight K, Latka M, Mizuno Y, Knowlton A, for the Intervention for Seropositive Injectors-Research Evaluation Team: Predictors of sharing injection equipment by HIV-seropositive injection drug users. J Acquir Immune Defic Syndr 2008, 49:447-450.

5. Stein M, Solomon D, Herman D, Anderson B, Miller I: Depression severity and drug injection HIV risk behaviors. Am J Psychiatry 2003, 160:1659-1662. 
6. Delgado M, Lundgren L, Deshpande A, Lonsdale J, Purington T: The association between acculturation and needle sharing among Puerto Rican injection drug users. Eval Program Plann 2008, 31:83-91.

7. Booth R, Kwiatkowski C, Mikulich-Gilbertson S, Brewster J, SalomonsenSautel S, Corski K, Sinitsyna L: Predictors of risky needle use following interventions with injection drug users in Ukraine. Drug Alcohol Depend 2006, 82(Suppl 1):49-55.

8. Buxton M, Vlahov D, Strathdee C, Des Jarlais D, Morse E, Ouellet L, Kerndt P, Garfein R: Association between injection practices and duration of injection among recently initiated injection drug users. Drug Alcohol Depend 2004, 75:177.

9. De P, Cox J, Boivin J, Platt R, Jolly A, Alexander P: HIV and HCV discordant injecting partners and their association to drug equipment sharing. Scand J Infect Dis 2009, 41:206-214.

10. Mandell W, Vlahov D, Latkin C, Oziemkowska M, Cohn S: Correlates of needle sharing among injection drug users. Am J Public Health 1994 84:920-923.

11. Metsch L, Pereyra M, Purcell D, Latkin C, Malow R, Gomez C, Latka M, for the INSPIRE Study Team: Correlates of lending needles/syringes among HIV-seropositive injection drug users. J Acquir Immune Defic Syndr 2007, 46(Suppl 2):72-79.

12. Seal K, Edlin B, Ochoa K, Tulsky J, Moss A, Hahn J: Risk of hepatitis B infection among young injection drug users in San Francisco: opportunities for intervention. West J Med 2000, 172:16-20.

13. Watters J, Estilo M, Clark G, Lorvick J: Syringe and needle exchange as HIV/ AIDS prevention for injection drug users. JAMA 1994, 271:115-120.

14. Doherty M, Garfein R, Monterosso E, Brown D, Vlahov D: Correlates of HIV infection among young adult short-term injection drug users. AIDS 2000, $14: 717-726$

15. Garfein R, Doherty M, Monterroso E, Thomas D, Nelson K, Vlahov D: Prevalence and incidence of hepatitis $C$ virus infection among young adult injection drug users. J Acquir Immune Defic Syndr Hum Retrovirol 1998, 18(Suppl 1):11-199.

16. Miller CL, Johnston C, Spittal PM, Li K, LaLiberte N, Montaner J, Schechter M: Opportunities for prevention: hepatitis $\mathrm{C}$ prevalence and incidence in a cohort of young injection drug users. Hepatol 2002, 36:737-742.

17. Bernstein E, Bernstein J, Levenson S: Project ASSERT: an ED based intervention to increase access to primary care, preventive services, and the substance abuse treatment system. Ann Emerg Med 1997, 30:181-189.

18. Skinner HA: The Drug Abuse Screening Test (DAST-10): Guidelines for administration and scoring. Toronto: Addiction Research Foundation; 1995.

19. Bernstein E, Ashong D, Heeren T, Winter M, Bliss C, Madico G, Bernstein J: The impact of a brief motivational intervention on unprotected sex and sex while high among drug-positive emergency department patients who receive STI/HIV VC/T and drug treatment referral as standard of care. AIDS Behav 2012, 16:1203-1216.

20. Ruggiero KJ, DelBen K, Scotti JR, Rabalais AF: Psychometric properties of the PTSD checklist-civilian version. J Trauma Stress 2003, 16:495-502.

21. Lankenau S, Teti M, Silva K, Bloom J, Harocopos A, Treese M: Initiation into prescription opioid misuse among young injection drug users. Int I Drug Policy 2012, 23:37-44.

22. Page K, Morris M, Hahn J, Maher L, Prins M: Injection drug use and hepatitis $C$ virus infection in young adult injectors: using evidence to inform comprehensive prevention. Clin Infect Dis 2013, 57(Suppl 2):32-38.

23. Peters A, Davies T, Richardson A: Multi-site samples of injecting drug users in Edinburgh: prevalence and correlates of risky injecting practices. Addiction 1998, 93:253-267

24. Costenbader EC, Astone NM, Latkin CA: The dynamics of injection drug users' personal networks and HIV risk behaviors. Addiction 2006, 101:1003-1013.

25. Hoffmann JP, Su SS, Pach A: Changes in network characteristics and HIV risk behavior among injection drug users. Drug Alcohol Depend 1997, 46:41-51.

26. Zerden L, López LM, Lundgren L: Needle sharing among Puerto Rican injection drug users in Puerto Rico and Massachusetts: place of birth and residence matter. Subst Use Misuse 2010, 45:1605-1622.

27. Centers for Disease Control and Prevention (CDC): HIV-associated behaviors among injecting-drug users - 23 cities, United States, May 2005-February 2006. MMWR Morb Mortal Wkly Rep 2009, 58:329-332.

28. Des Jarlais D, Diaz T, Perlis T, Vlahov D, Maslow C, Latka M, Rockwell R, Edwards V, Friedman S, Monterroso E, Williams I, Garfein R: Variability in the incidence of human immunodeficiency virus, hepatitis B virus, and hepatitis $C$ virus infection among young injecting drug users in New York City. Am J Epidemiol 2003, 157:467-471

29. Thorpe L, Ouellet L, Hershow R, Bailey S, Williams I, Williamson J, Monterroso $E$, Garfein R: Risk of hepatitis C virus infection among young adult injection drug users who share injection equipment. Am J Epidemiol 2002, 155:645-653.

doi:10.1186/1940-0640-8-20

Cite this article as: Tassiopoulos et al:: Age and sharing of needle injection equipment in a cohort of Massachusetts injection drug users: an observational study. Addiction Science \& Clinical Practice 2013 8:20.

\section{Submit your next manuscript to BioMed Central and take full advantage of:}

- Convenient online submission

- Thorough peer review

- No space constraints or color figure charges

- Immediate publication on acceptance

- Inclusion in PubMed, CAS, Scopus and Google Scholar

- Research which is freely available for redistribution

Submit your manuscript at www.biomedcentral.com/submit
Ciomed Central 